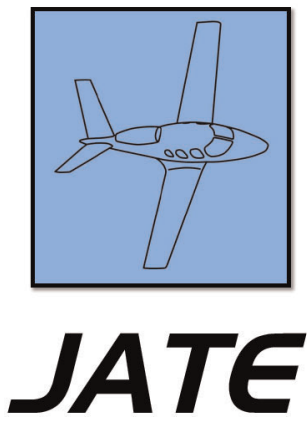

Journal of Aviation Technology and Engineering 8:2 (2019) 40-49

\title{
Pilot Study: Measuring Attitudes Toward Ramp Resource Management-The Influence of National Culture
}

\author{
Nadine G. Muecklich and Hans-Joachim K. Ruff-Stahl \\ Embry-Riddle Aeronautical University
}

Ivan Sikora

University of West London

\begin{abstract}
Ramp resource management (RRM) is a highly flight-safety-relevant, but to date widely overlooked, part of the air transportation system. Organizational, national, professional, and safety cultures play an important role in setting up resource management and training. This pilot study evaluates the influence of national culture on attitudes toward RRM, based on Geert Hofstede's Values Survey Module. A slightly adapted version of this survey module was distributed to ramp personnel in Germany and national cultural indices were generated. A one-way analysis of variance revealed that, while some influence of national culture in RRM could be concluded, the majority of the results were not statistically significant (critical $p$-value $<0.05$ ). In spite of the broad acceptance of the influence of national culture on crew resource management, the results could indicate weaknesses in current cultural values survey tools. Clearly, this pilot study indicates that further research in the field of RRM and culture is needed for a reliable evaluation of current RRM and training methods.
\end{abstract}

Keywords: ramp resource management, national culture, ground operations

\section{Introduction}

This pilot study evaluates the influence of national culture on ramp resource management (RRM). RRM is a crew resource management (CRM) derivate, which is currently under development and is intended to enhance the coordination, communication, and efficiency of aircraft turnaround with the purpose of increasing the overall safety of ground operations (Balk et al., 2012). Specifically, the aim of this paper is to find out whether and how national cultures have an influence on attitudes toward RRM, thereby directly impacting the safety of ramp and resulting flight operations.

Yet at first, it is important to understand how RRM is defined and the context in which it is applied. RRM in general refers to the efficient and effective use of all available ramp resources during ground operations, to include people, equipment, and information (Balk et al., 2012). The overall aim is to decrease incidents and accidents involving ramp personnel and damage to aircraft or equipment. At the same time, RRM seeks to increase operational efficiency by the same methodology: advancing the communication and coordination of all available resources on the ramp. It is assumed that individuals' 
awareness and knowledge in their field of operation are crucial for safe, efficient, and effective ramp operations. Thus, individual and group attitudes play a key role for the successful implementation of RRM, making it important to know the characteristics of the target group receiving RRM and training. This target group includes management, direct supervisors or team leaders, and permanent and temporary employees. Ramp operations personnel are characterized by persons with basic education, being trained on mainly technical skills, having a high turnover, and being a maledominated domain (Balk et al., 2012).

CRM and training have received much attention in the aviation industry in recent years. National culture has been shown to be an influencing factor on effective cockpit communication, especially during abnormal occurrences (Quinn \& Sikora, 2017).

In contrast to CRM, RRM has been widely overlooked as a risk control measure in the air transportation system and less guidance and fewer regulations for a coherent RRM procedure are available. Particularly, factors such as national culture do not yet receive sufficient attention in the execution of RRM. While CRM broadly uses Geert Hofstede's six cultural dimensions to measure the influence of national culture (Hofstede, Hofstede, \& Minkov, 2010), this method is not yet considered in the development of RRM guidance materials (e.g., ACI World Operational Safety Sub-Committee, 2010; ECAST, 2013; FAA, 2007). Not every concept of CRM may be transferable to RRM, but factors such as national culture and its influence on ramp operations should be examined. On a typical ramp of an international airport, personnel from different companies and many different national cultures can be found. During the time when this study was conducted, the workforce on the ramp at the Cologne/Bonn airport (IATA: CGN) in Germany consisted of mainly German, Turkish, and Greek employees. In addition, airlines from foreign countries sometimes bring their own ground operations workforce with them and thus further increase the number of national cultures in this environment. Yet, despite diverse national and cultural backgrounds, ramp personnel must be coherently managed and trained for the common goal of a safe and efficient operation. To achieve this goal, ramp resource training is the major means of communicating policies, procedures, and desired outcomes (Balk et al., 2012). For example, the European Commercial Safety Team-Ground Safety Working Group (ECAST-GSWG) has developed a training syllabus that aims to provide resource management contents for ground operations. It includes best practices and sufficient insight with the goal of improving attitudes towards safety. This training syllabus contains five major topics: (1) the turnaround process, (2) safety regulations, (3) teamwork, (4) threat and error management, and (5) human performance and limitations. The third topic, "teamwork," addresses cultural, ethnic, and educational differences. Yet within this topic, the subject of national culture is only mentioned, but not defined, and hence ultimately not adequately addressed (ECAST, 2013). Further, while the training syllabus suggests a framework of what topics need to be included in RRM, it does not define these topics or provide guidance in what detail these issues need to be trained. The same applies for the Airport Council International Airside Safety Handbook (2010) and the Federal Aviation Administration (FAA) Human Factors Manual for Airport Operations (2007). In general, all current guidance materials provide an overview and structure of ground operations components, address several human factor topics (e.g. teamwork, communication, threat management, fatigue, etc.), and recommend a setup regarding RRM or human factors training for ramp operations. But none of them identifies the impact of national culture for the acceptance and execution of RRM. Within the scope of this paper, this omission potentially has grave consequences.

RRM is required as part of the safety management system of the respective company, but has no stand-alone requirements as compared to the extensive contents of CRM training. While national culture is mentioned indirectly in a few cases, the focus is on concepts such as just culture and safety culture (e.g., ACI World Operational Safety SubCommittee, 2010; FAA, 2007).

Hofstede defines culture as "the collective programming of the mind distinguishing the members of one group or category of people from others" (Hofstede, n.d.). The six dimensions are (1) Power Distance (PDI), (2) Individualism (IDV), (3) Masculinity (MAS), (4) Uncertainty Avoidance (UAI), (5) Long-Term Orientation (LTO), and (6) Indulgence (IND) (Hofstede et al., 2010) and are measured in two directions: low and high.

Starting with PDI, an effective human interaction in the cockpit is crucial for the safety of flight operation. The impact of national culture on flight safety has been shown in various accidents. Exemplarily, the root cause of the Korean Air Flight 801 crash in 1997 has been identified as fatigue and poor communication. More specifically, the high PDI within the Korean culture led to inefficient and unsafe communication, causing the pilot to land the aircraft in spite of the first officer's factual disagreement (NTSB, 2000). PDI is about the degree of unequal distribution of power and in how far this is accepted in a national culture. For nations with low PDI, forms of hierarchy are accepted and not scrutinized. Everybody knows their place and critique from someone in a lower position to someone in a higher position is rare and unwelcomed. A high PDI means the opposite: power should be more equally distributed and inequalities are questioned (Hofstede et al., 2010).

Second, high IDV exists when an individual is only be expected to be responsible for him/herself and direct relatives. Low IDV or collectivism is the stage in a society when people think as "we" rather than in terms of "I." Hofstede describes collectivism coming with an "unquestioned loyalty" (Hofstede et al., 2010). 
Third, MAS in the cultural context refers to aiming for success. More detailed characteristics of MAS are, for example, heroism and materialism. Femininity, on the other hand, refers to more tender characteristics with a strong focus on cooperation in the entire group (including weak and strong members), and generally focuses on "quality of life" issues (Hofstede et al., 2010).

Fourth, UAI is about control. It describes how comfortable one feels when not being able to control a situation or the future. It is about one's attitude toward uncertainty and ambiguity of information or a situation and the strong or weak aim to control it anyway (Hofstede et al., 2010).

Fifth, low LTO (or Short-Term Normative) is focused on traditions and existing norms. Changes for the future are approached skeptically. On the other hand, high LTO is described with more pragmatic and open attitudes toward future developments (Hofstede et al., 2010).

Currently, the final dimension is termed IND versus restraint. IND refers to the acceptance and even need to have fun and joy. Restraint restricts fun and joy by social norms (Hofstede et al., 2010).

Different cultures show differences in the dimensional scores (Hofstede, n.d.). These differences, in turn, significantly affect interactions on the ramp, not only in humanhuman interactions, but also in human-equipment and human-systems interactions. For example, different scores in LTO can affect whether and how new rules or systems are accepted and implemented by the ramp personnel. A team member who is focused on the existing and not on long-term progress can have an impact on the success of implementing new rules or systems, e.g., simply refusing to learn or accepting change. Different cultures have an influence on the handling of changes and the way new procedures are implemented. Ramp safety and efficiency depend on the human element; hence, every influence on the individual or the team might directly or indirectly impact the entire operation.

Current research in CRM claims that national culture is a decisive influence (Kanki, Helmreich, \& Anca, 2010). Hence and following the CRM example, RRM may be considered as an effective tool to control safety, efficiency, and effectiveness. Yet in contrast to CRM, the influence of national cultures might be underestimated in RRM. Consequently, the hypothesis for this pilot study was that subjects from different national backgrounds score significantly different on a survey designed to measure six national cultural indices.

\section{Methodology}

A pilot study has been chosen as a preliminary study for determining the feasibility of the methods for the desired research question: Does national culture influence the attitude of ramp personnel toward RRM and training? For this pilot study, a quantitative approach is followed.
A survey is used to collect data and measure the attitudes of ramp personnel in Germany, based on the Value Survey Module (VSM) 2013 Questionnaire as developed by Hofstede and Minkov (2013). The following three groups are distinguished: (1) German, (2) German with different nationality at birth or dual nationality, and (3) not German, but working in Germany.

\section{Research Model}

For this research project, a quantitative approach has been followed. A survey module was used to collect data and measure the attitudes of ramp personnel in Germany. This survey quantified attitudes and opinions and was based on the VSM 2013 Questionnaire as developed by Hofstede and Minkov (2013). Analysis and evaluation were executed using the VSM 2013 manual and an analysis of variance (ANOVA). Survey questions were answered using five-point scales. The responses were grouped based on national background into three groups. Because of the limited number of responses for each nationality, it was not feasible to compare individual nationalities. Therefore, the researcher decided for the following three groups in the first survey run: (1) German, (2) German with different nationality at birth or dual nationality, and (3) not German, but working in Germany. The survey questions, as well as part of the analysis, were based on Geert Hofstede's decade-long research. The six cultural dimensions have been defined by Hofstede and were used in this research to detect if, where, and how far differences exist between the three or two groups of national background.

\section{Research Population}

The research population consisted of ramp personnel working in Germany. Survey participants were not a chosen set of this population, but agreed to voluntarily participate. In total, 40 people participated in the pilot study. The total population of airport ramp personnel in Germany amounts to approximately 30,000 in different ramp working areas, including aircraft load/unload, fueling, aircraft maintenance, aircraft marshalling and towing, and many more (Vereinte Dienstleistungsgewerkschaft (verdi), n.d.). For the purpose of this study, aircraft maintenance personnel were not included, because of significantly different characteristics in average education, tasks, and working area.

\section{Data Sources}

The survey was the sole data source for conducting this research project and contains 30 questions from the VSM 2013 (Hofstede, 2013). The German version of the VSM 2013 was retrieved from Geert Hofstede's website (Hofstede, 2014). The sampling technique was a purposive, 
convenience sampling of ramp personnel because the researcher was unable to access a wider population for this research. In addition, the survey was distributed only to ramp personnel working in Germany and depended on voluntary participants.

\section{Treatment of Data}

\section{General}

The data collected were first distributed into three groups: (1) German participants, (2) German participants with dual nationality or a different nationality at birth, and (3) participants with a different, non-German, nationality, but working and living in Germany. These three groups could then be compared to each other. To evaluate the data, the VSM 2013 manual as developed by Hofstede and Minkow was used first. Afterwards, an ANOVA was conducted to compare group means and ultimately, to decide whether the hypothesis can be supported or must be rejected.

\section{VSM 2013}

The survey was based on the VSM 2013 as developed by Hofstede and Minkov. The concept of the VSM 2013 aims to compare values, beliefs, and attitudes from different nations/countries with each other. The first six of 30 questions are demographic questions, while the following 24 questions are content questions regarding the six cultural dimensions, thus having four questions for each dimension. Hofstede's questions on attitudes and opinions influenced by national culture were developed since the 1960s. The VSM 2013 is the most recent version, which integrates all national cultural dimensions from Hofstede et al. (2010). For this research project, the 24 content questions have not been altered, whereas the six demographic questions have been adapted to this study, e.g., asking for the individual's current working position on the ramp. In order to evaluate the responses, the VSM 2013 manual was used, aiming to compute scores for the six cultural dimensions. Within this manual, Hofstede (2013) describes formulas for the index calculation of the 24 content questions for the purpose of calculating index scores. The following formulas were used to calculate indices for the six cultural dimensions:

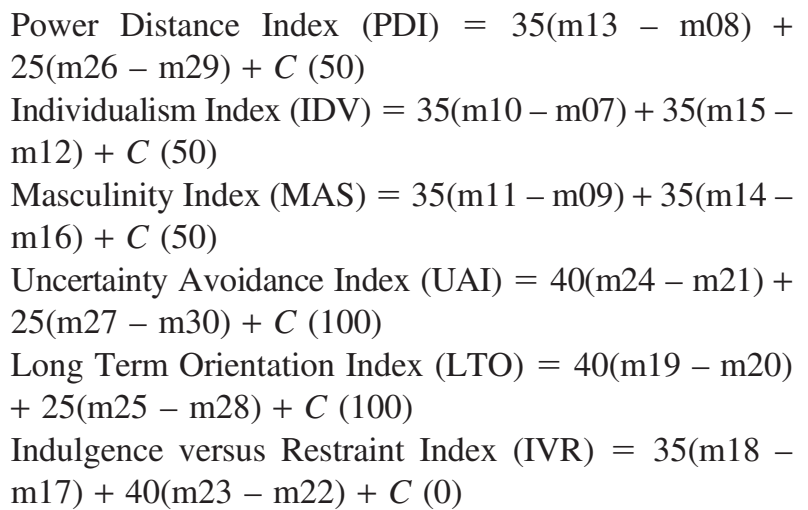

The formulas were retrieved from the VSM 2013 manual to calculate the index scores. For example, m13 stands for the mean answer of question 13. All formulas were computed for the three groups of national background and then compared to each other. The parameter $C$ in the individual formulas is a constant that is chosen by the researcher to shift the scores to values between 0 and 100 .

\section{ANOVA and Tukey honestly significant difference (HSD)}

The one-way ANOVA was used an additional analysis tool and the basis for accepting or rejecting the alternative hypothesis. The $p$-value for accepting or rejecting a significant difference of the answers was set to $p \leq 0.05$ (Aron, Coups, \& Aron, 2011). For all content questions with significant different results, a Tukey HSD test was conducted to determine between which groups the significant difference actually exists. The Tukey HSD test is a post hoc test and compares the means of all three groups to each other. It complements ANOVA by identifying whether there is a significant difference between all three groups or if the significance is present, for example, only between two of the three groups, and for which groups specifically. Tukey HSD was conducted only for those questions for which ANOVA indicated significance.

\section{Results}

In total, 40 people from 8 nations, i.e., (1) German, (2) Polish, (3) Greek, (4) Hungarian, (5) Macedonian, (6) Bosnian, (7) Croatian/Jugoslav, and (8) Albanian, participated in the survey. $77.5 \%$ of the participants were male, $22.5 \%$ female. Similar characteristics were previously researched and described by the EASA-ECAST Ground Safety Working Group and experts from the NLR (Balk et al., 2012) and thus indicate a valid sample for the pilot study.

\section{VSM 2013 Manual-Analysis of the Survey}

Table 1 shows indices for the six cultural dimensions. The constant $C$ is added in the formulas to shift the indices to values between 0 and 100. A value above 70 is considered a high index, while a value below 30 is considered low for the specific dimensional index. Values between 30 and 70 are not specifically high or low, but are compared within their dimension to analyze the difference.

The average difference between the lowest and the highest score within the indices is 39.65. Two of the six indices show larger differences between at least two of the three groups with a difference above 40 between the lowest and the highest score. Each of the cultural dimensions shows at least one value that is considered high $(>70)$ or low $(<30)$. Hence, the PDI for group 2 is high, the IDV for group 2 is low, the MAS for group 1 is high, the UAI for group 2 is low, the LTO for groups 1 and 2 is high, and the IVR for 
Table 1

Six cultural dimensions-indices.

\begin{tabular}{llcl}
\hline Cultural dimension & German & $\begin{array}{c}\text { German with different nationality } \\
\text { at birth or dual nationality }\end{array}$ & $\begin{array}{c}\text { Other nationality, } \\
\text { but working in Germany }\end{array}$ \\
\hline PDI & 65.35 & $\mathbf{8 5 . 4 5}$ (high) \\
IDV & 57.35 & $\mathbf{1 8 . 8 5}($ low $)$ & 49.83 \\
MAS & $\mathbf{7 5 . 9}($ high $)$ & 38.45 & 55.6 \\
UAI & 68.1 & $\mathbf{2 4 . 4}($ low $)$ & 50.1 \\
LTO & $\mathbf{7 7 . 9 5}$ (high) & $\mathbf{8 7 . 3 5}$ (high) \\
IVR & 66 & 44.4 & 41.4 \\
\hline
\end{tabular}

Note. The table provides an overview of the indices for the six cultural dimensions.

Table 2

ANOVA of the VSM 2013 content questions.

\begin{tabular}{|c|c|c|c|c|c|}
\hline Question & German: mean & $\begin{array}{l}\text { German with different } \\
\text { nationality at birth or dual: mean }\end{array}$ & Non-German: mean & $p$-Value (ANOVA) & $\begin{array}{l}\text { Significant difference: yes/no } \\
\quad(\text { critical } p \text {-value }<\mathbf{0 . 0 5})\end{array}$ \\
\hline Q7 & 2.16 & 2.22 & 2.17 & 0.98 & No \\
\hline Q8 & 1.74 & 1.78 & 2 & 0.57 & No \\
\hline Q9 & 2.16 & 2.11 & 2.08 & 0.97 & No \\
\hline Q10 & 1.42 & 1.22 & 1.58 & 0.4 & No \\
\hline Q11 & 2.4 & 1.67 & 1.67 & 0.01 & Yes \\
\hline Q12 & 1.68 & 2.11 & 1.67 & 0.34 & No \\
\hline Q13 & 2.05 & 2 & 2 & 0.97 & No \\
\hline Q14 & 2.32 & 1.89 & 2.75 & 0.06 & No \\
\hline Q15 & 2.63 & 2.22 & 2.42 & 0.62 & No \\
\hline Q16 & 1.79 & 1.78 & 2.08 & 0.59 & No \\
\hline Q17 & 2.63 & 2.56 & 2.08 & 0.29 & No \\
\hline Q18 & 2.95 & 2.56 & 2.58 & 0.35 & No \\
\hline Q19 & 2.11 & 2.56 & 1.83 & 0.09 & No \\
\hline Q20 & 2.63 & 3.22 & 2.67 & 0.26 & No \\
\hline Q21 & 3.11 & 3.78 & 3.58 & 0.18 & No \\
\hline Q22 & 2 & 2 & 1.58 & 0.14 & No \\
\hline Q23 & 3.37 & 3.11 & 3.17 & 0.771 & No \\
\hline Q24 & 2.05 & 1.89 & 1.5 & 0.22 & No \\
\hline Q25 & 2.11 & 2.44 & 1.58 & 0.19 & No \\
\hline Q26 & 3.16 & 3.89 & 2.58 & 0.01 & Yes \\
\hline Q27 & 2.47 & 2.22 & 3.33 & 0.02 & Yes \\
\hline Q28 & 2.16 & 1.89 & 2.58 & 0.36 & No \\
\hline Q29 & 2.58 & 2.78 & 2.75 & 0.86 & No \\
\hline Q30 & 2.05 & 2.22 & 2 & 0.83 & No \\
\hline
\end{tabular}

group 3 is high. These high and low values are specifically identified to evaluate in which dimensions and in which groups more extreme values exist. The dimensions with their individual characteristics will help to identify recommendations to improve future RRM and training.

\section{ANOVA Results}

Table 2 shows the group means and the ANOVA results. Only for three questions $(11,26$, and 27) could a significant difference between the answers be observed. In five questions, the similarities of answers are close to identical. Question 11 asks: "How important is it to you to have pleasant people to work with?", question 26 asks: "How often, in your experience, are subordinates afraid to contradict their boss?", and question 27 asks for the opinion on the following statement: "One can be a good manager without having a precise answer to every question that a subordinate may raise about his or her work." All three questions directly refer to the working environment and/or the contact with superiors. The PDI, UAI, and MAS use one of these significant different means. Thus, even if most of the questions show no significant difference of means between the three groups, three of the six cultural dimensions are influenced by significant differences in the mean of questions. Tables 3-11 show the ANOVA and Tukey HSD results for the statistically significant questions 11, 26, and 27 .

Question 11, on how important it is to have pleasant people to work with, shows that ANOVA concludes for a significant difference between the means of the three groups. The Tukey HSD test displays that there is a significant difference between group 1 and group 2, and between group 1 and group 3, but not between group 2 and group 3 . This implies that there is a difference between German ramp personnel and ramp personnel with a different cultural background. 
Table 3

Column statistics for question 11.

\begin{tabular}{lcccc}
\hline Column & $\boldsymbol{N}$ & Mean & Standard deviation & Standard error \\
\hline German & 19 & 2.37 & 0.83 & 0.19 \\
German, but diff. nat. at birth & 9 & 1.67 & 0.5 & 0.167 \\
Non-German & 12 & 1.67 & 0.65 & 0.188 \\
\hline
\end{tabular}

Table 4

ANOVA results for question 11.

\begin{tabular}{lccccc}
\hline Source & DF & SS & MS & $\boldsymbol{F}$-Statistic & $\boldsymbol{p}$-Value \\
\hline Columns & 2 & 4.91 & 2.46 & 4.76 & 0.19 \\
Error & 37 & 19.09 & 0.52 & - & - \\
Total & 39 & 24 & - & - & - \\
\hline
\end{tabular}

Table 5

Tukey HSD results (95\% level) for question 11 .

German subtracted from:

\begin{tabular}{lcccc}
\hline & Difference & Lower & Upper & $p$-Value \\
\hline German, but diff. nat. at birth & -0.70 & -1.41 & 0.01 & 0.05 \\
Non-German & -0.70 & -1.35 & -0.05 & 0.03 \\
\hline German, but diff. nat. at birth subtracted from: & Difference & Lower & Upper & $p$-Value \\
\hline Non-German & 0 & -0.77 & 0.77 & 1 \\
\hline
\end{tabular}

Table 6

Column statistics for question 26.

\begin{tabular}{lcccc}
\hline Column & $\boldsymbol{N}$ & Mean & Standard deviation & Standard error \\
\hline German & 19 & 3.16 & 0.68 & 0.16 \\
German, but diff. nat. at birth & 9 & 3.89 & 1.17 & 0.39 \\
Non-German & 12 & 2.58 & 1.24 & 0.36 \\
\hline
\end{tabular}

Table 7

ANOVA results for question 26.

\begin{tabular}{lrcccc}
\hline Source & DF & SS & MS & $\boldsymbol{F}$-Statistic & $\boldsymbol{p}$-Value \\
\hline Columns & 2 & 8.77 & 4.38 & 4.46 & 0.02 \\
Error & 37 & 36.33 & 0.98 & - & - \\
Total & 39 & 45.1 & - & - & - \\
\hline
\end{tabular}

Table 8

Tukey HSD results (95\% level) for question 26.

German subtracted from

\begin{tabular}{lcccc}
\hline & Difference & Lower & Upper & $p$-Value \\
\hline German, but diff. nat. at birth & 0.73 & -0.25 & 1.71 & 0.18 \\
\hline Non-German & -0.57 & -1.47 & 0.32 & 0.27 \\
\hline German, but diff. nat. at birth subtracted from & Difference & Lower & Upper & $p$-Value \\
\hline Non-German & -1.31 & -2.37 & -0.24 & 0.01 \\
\hline
\end{tabular}


Table 9

Column statistics for question 27.

\begin{tabular}{lrcr}
\hline Column & $\boldsymbol{N}$ & Mean & Standard deviation \\
\hline German & 19 & 2.47 & 1.02 \\
German, but diff. nat. at birth & 9 & 2.22 & 0.44 \\
Non-German & 12 & 3.33 & 0.15 \\
\hline
\end{tabular}

Table 10

ANOVA results for question 27.

\begin{tabular}{lrrrrr}
\hline Source & DF & SS & MS & F-Statistic & $\boldsymbol{p}$-Value \\
\hline Columns & 2 & 7.82 & 3.91 & 4.14 \\
Error & 37 & 34.96 & 0.95 & -0.02 \\
Total & 39 & 42.78 & - & - \\
\hline
\end{tabular}

Table 11

Tukey HSD results (95\% level) for question 27.

German subtracted from:

\begin{tabular}{lccc}
\hline & Difference & Lower & Upper \\
\hline German, but diff. nat. at birth & -0.25 & -1.21 & 0.71 \\
Non-German & 0.86 & -0.02 & 0.79 \\
\hline
\end{tabular}

German, but diff. nat. at birth subtracted from:

\begin{tabular}{lcccc}
\hline & Difference & Lower & Upper & $\boldsymbol{p}$-Value \\
\hline Non-German & 1.11 & 0.06 & 2.16 \\
\hline
\end{tabular}

The results of the ANOVA for question 26 imply a significant difference between the three means of responses. Then, the Tukey HSD test revealed that this significant difference is only applicable between group 2 and group 3, because only this comparison results in a $p$-value below 0.05 . Thus, even if the difference is statistically significant, this must not be true between all three groups.

The results of question 27 indicate a significant difference between the group means, but again, this difference is not true between all group combinations. Group 1 and group 3, and group 2 and group 3 are significantly different from each other. On the other hand, group 1 and group 2 are unlikely to have a significant difference.

In the next section, assumptions for this outcome are discussed.

\section{Discussion}

In general, the aim of the pilot study was to determine the feasibility of the research methods for the research question and hypothesis. This preliminary research tested the research methods with a small sample size. Thus, it was a necessary step before performing the full research project on the hypothesis.

Survey

Based on the ANOVA results, no significant difference between all or at least most answers could be observed, and therefore the influence of national culture on attitudes toward RRM seems insignificant. Nevertheless, and in contrast to the ANOVA procedure, the VSM 2013 shows differences within the indices. Especially, the VSM 2013 analysis of uncertainty avoidance (UAI) and long-term orientation (LTO) show considerable differences. In addition, the different groups show specific high (score $>70$ ) and low (score $<30$ ) values in various cultural dimensions. For example, a high PDI (85.45) was observed for group 2 in the first survey run-German with a different nationality at birth or dual nationality. This high score is an indicator that people from this group tend to accept inequalities in the distribution of power and a hierarchical order of power tends to be the norm in this group. For comparison, similar values were observed for the United Arabic Emirates (PDI $=90)$, Albania (PDI $=90)$, China (PDI $=80)$, and Bangladesh (PDI $=80$ ) (Hofstede \& Hofstede, 2018).

Next, the IDV for group 2 is low (18.85). Based on these results, this group of people is more collectivistically oriented with a stricter "we"-feeling within the group. A reason for this can originate from their cultural background, e.g., Turkish or Greek. The PDI and IDV for the second group are higher than the indices for the other groups. The cultural identity shows split results for German nationals who have a different nationality at birth or those who have a dual nationality. These results suggest that these people may be influenced by their family and friends from the same or similar national backgrounds. Parental education of national values during the childhood can also 
influence the people of this group in their adult life (Hofstede et al., 2010).

Third, the MAS score for group 1 is high (75.9). The German group shows this high MAS score and, according to Hofstede et al. (2010), this group is more competitive with a focus on material success, achievement, heroism, and assertiveness. For comparison, similar MAS scores have been observed for Austria (MAS = 79) and Hungary (MAS = 88). The MAS score for Germany is 66 (Hofstede $\&$ Hofstede, 2018). The other two groups in this research do not show a similar focus on materialism.

The UAI of group 2 is low (24.4); therefore, the members of this group do feel more comfortable or relaxed with not knowing what the future will bring. People in this group tend to feel better if the future is uncertain or ambiguous. Similar results have been observed for China (UAI $=30)$ and Jamaica $(\mathrm{UAI}=13$ ) (Hofstede \& Hofstede, 2018).

Fourth, the LTO scores for groups 1 and 2 are high (77.95 and 87.35). For these two groups, the high LTO means the people encourage change to reinitialize for the future. In other words, today means preparing for tomorrow. In the research of Hofstede and Hofstede (2018), a high LTO was observed for Germany (LTO = 83) and Belgium $(\mathrm{LTO}=82)$.

The IVR for group 3 is high (81.1). This dimension shows a score between 0 and 100 for indulgence versus restraint; therefore, a high score indicates that activities for fun and joy are more restricted by social norms and less by the individual. As a comparison, a high IVR was observed for Angola (IVR = 83) (Hofstede \& Hofstede, 2018).

Differences and similarities in the six cultural dimension scores are assumed to be influenced by the working and living environment; therefore on the one hand by the German culture, but on the other hand by the "mother" culture (Hofstede et al., 2010).

Nevertheless, the following questions/assumptions arise from the results. (1) Only people from the same national culture can be grouped and compared to another. A second national cultural background is to be integrated in a separate group (i.e., people with two nationalities like German and Turkish must be grouped in a German/Turkish group). (2) The research method, VSM 2013 manual analysis, might not be feasible when researching the attitudes and behavior of ramp personnel. (3) Organizational culture might have a more significant influence on ramp personnel and may decrease the significance of influence on national culture.

Additional limitations of this study should be noted. First, the results do not reflect the national cultural influence in specific situations (e.g., stress situations, working with women, or working with a specific other culture). Hence, it must be considered that different, non-routine situations may reveal attitudes and behavior that are influenced by national culture.
Second, the purposive non-probability sampling led to a focus on a specific group of people and has limited the population that will be asked. This has happened in two ways: (1) the survey was only distributed to ramp personnel working in Germany and (2) the survey was primary distributed via social media. Additionally, the sampling method was convenient sampling, which means that the research has been dependent on the relatively small number of subjects who voluntarily responded to the survey.

\section{Recommendations}

Based on the results of the pilot study, further research with different research methods is recommended, considering a possible intra-influence of national, organizational, and safety cultures. Further research should aim to reveal more detailed information on whether to accept or reject the current hypothesis and why, using additional research methods. Qualitative and quantitative research should also include organizational, professional, and safety cultures and their interference with national culture. Specifically, the question should be researched as to whether organizational, professional, or safety cultures change the influence of national culture in an organization. Even though further research must be conducted to reveal more information about the influence of culture, human factors training for ground operations personnel is recommended to include cultural components. The aim of this inclusion is to create awareness of ground personnel on the individual differences, including different national cultures. This is in line with the ECAST Ground Safety Working Group RRM training syllabus on "Cultural, ethnic and educational difference"(ECAST, 2013). Syllabi are living documents and should be continuously enhanced and improved by research, also from within each organization and from relating experiences.

\section{Conclusion}

The primary aim of this pilot study was reached: improving knowledge and understanding regarding the management of ramp resources. Yet, based on the analysis of the survey through ANOVA, the hypothesis had to be rejected. A significant influence of national culture on RRM could not be measured. On the other hand, an analysis of the survey based on the VSM 2013 methodology did reveal considerable differences in the six cultural dimensions. But similar to the CRM development process, RRM still needs a lot of research to further examine these differences and derive lessons learned to adapt and develop the characteristics, standard procedures, and best practices of RRM. This research project was intended as a first step in this direction. Further research, using the experiences from this study, should aim to broaden the knowledge on the influence of culture on RRM, but as well the intra-influence 
between national, organizational, professional, and safety cultures. In the end, the training concept of RRM should reflect resulting findings.

\section{References}

Airports Council International. (2010). Airside Safety Handbook. Retrieved from skybrary.aero: https://www.skybrary.aero/bookshelf/books/ 3171.pdf

Aron, A., Coups, E. J., \& Aron, E. N. (2011). Statistics for the Behavioural \& Social Sciences: A brief course (5th ed.). New York, NY: Prentice Hall.

Balk, A. D., Boland, E. J., Nabben, A. C., Bossenbroek, J. W., Clifton-Welker, N., Landauer, N., ... Schaffner, B. (2012, December 1). RRM training syllabus supporting document NLR-TR-2012-483-tr. Retrieved from https://www.easa.europa.eu/document-library/generalpublications/rrm-training-syllabus-supporting-document-nlr-tr-2012483-tr

ECAST. (2013, January 1). Ramp resource management. Retrieved from http://essi.easa.europa.eu/ecast/?page_id=1321

FAA. (2007, September). Human Factors Manual in Airport Operations. Retrieved from faa.gov: https://www.faa.gov/about/initiatives/ maintenance_hf/library/documents/media/support_documentation/ opsman_ramp_final.pdf

Hofstede, G. (2013, May). Values Survey Module 2013. Retrieved from http://geerthofstede.com/research-and-vsm/vsm-2013/

Hofstede, G. (2014, January 17). VSM 2013 German 20140117. Retrieved from https://geerthofstede.com/research-and-vsm/vsm-2013/

Hofstede, G. (n.d.). National culture. Retrieved from https://www. hofstede-insights.com/models/national-culture/

Hofstede, G., \& Hofstede, G. J. (2018). Compare countries. Retrieved from https://www.hofstede-insights.com/product/compare-countries/

Hofstede, G., Hofstede, G. J., \& Minkov, M. (2010). Cultures and organizations: Software of the mind (3rd ed.). New York, NY: McGraw-Hill USA.

Kanki, B., Helmreich, R., \& Anca, J. (2010). Crew resource management (2nd ed.). Ashgate Publishing.

NTSB. (2000, January 13). Aircraft accident report: Controlled flight into terrain Korean Air Flight 801. Retrieved from https:/www.ntsb.gov/ investigations/AccidentReports/Reports/AAR0001.pdf

Quinn, A., \& Sikora, I. (2017, June). The right stuff “v" the right (safe) thing. Journal of Space Safety Engineering, 4(2), 77-82.

Vereinte Dienstleistungsgewerkschaft (verdi). (n.d.). Was sind Bodenverkehrsdienste (BVD)? Retrieved from https://www.verdi-airport.de/203

\section{Appendices}

Appendix 1: Survey based on VSM 2013

$\underline{\text { Some information about yourself (for statistical purposes): }}$

Q1: Are you:

- Male

- Female

Q2: How old are you?

- $18-19$

- 20-24

- 25-29

- 30-34

- 35-39
- 40-49

- 50-59

- 60 or over

Q3: How many years of formal school education (or their equivalent) did you complete (starting with primary school)?

- 10 years or less

- 11 years

- 12 years

- 13 years

- 14 years

- 15 years

- 16 years

- 17 years

- 18 years or over

Q4: What is your current position on the ramp?

- Ramp employee

- Ramp supervisor/team leader/other supervisory position

- Ramp management

- Other

Q5: What is your nationality?

Q6: What was your nationality at birth (if different)?

Please think of your current job on an airport ramp to answer the questions. The scale for this first part is as follows:

$1=$ of utmost importance

$2=$ very important

$3=$ of moderate importance

$4=$ of little importance

$5=$ of very little or no importance

How important would it be to you to... (please click one answer in each line across)?

Q7: ... have sufficient time for your personal or home life?

$\begin{array}{lllll}1 & 2 & 3 & 4 & 5\end{array}$

Q8: ... have a boss (direct superior) you can respect?

$\begin{array}{lllll}1 & 2 & 3 & 4 & 5\end{array}$

Q9: ... get recognition for good performance?

$\begin{array}{lllll}1 & 2 & 3 & 4 & 5\end{array}$

Q10: ... have security of employment?

$\begin{array}{lllll}1 & 2 & 3 & 4 & 5\end{array}$

Q11: ... have pleasant people to work with?

$\begin{array}{lllll}1 & 2 & 3 & 4 & 5\end{array}$

Q12: ... do work that is interesting?

$\begin{array}{lllll}1 & 2 & 3 & 4 & 5\end{array}$

Q13: ... be consulted by your boss in decisions involving your work?

$\begin{array}{lllll}1 & 2 & 3 & 4 & 5\end{array}$

Q14: ... live in a desirable area?

$\begin{array}{lllll}1 & 2 & 3 & 4 & 5\end{array}$

Q15: ... have a job respected by your family and friends?

$\begin{array}{lllll}1 & 2 & 3 & 4 & 5\end{array}$ 
Q16: ... have chances for promotion?

$\begin{array}{lllll}1 & 2 & 3 & 4 & 5\end{array}$

In your private life, how important is each of the following to you (please click one answer in each line across):

Q17: ... keeping time free for fun?

$\begin{array}{lllll}1 & 2 & 3 & 4 & 5\end{array}$

Q18: ... moderation: having few desires?

$\begin{array}{lllll}1 & 2 & 3 & 4 & 5\end{array}$

Q19: ... doing a service to a friend?

$\begin{array}{lllll}1 & 2 & 3 & 4 & 5\end{array}$

Q20: ... thrift (not spending more than needed)?

$\begin{array}{lllll}1 & 2 & 3 & 4 & 5\end{array}$

Q21: How often do you feel nervous or tense?

- Always

- Usually

- Sometimes

- Seldom

- Never

Q22: Are you a happy person?

- Always

- Usually

- Sometimes

- Seldom

- Never

Q23: Do other people or circumstances ever prevent you from doing what you really want to?

- Yes, always

- Yes, usually

- Sometimes

- No, seldom

- No, never

Q24: All in all, how would you describe your state of health these days?

- Very good

- Good

- Fair

- Poor
- Very poor

Q25: How proud are you to be a citizen of your country?

- Very proud

- Fairly proud

- Somewhat proud

- Not very proud

- Not proud at all

Q26: How often, in your experience, are subordinates afraid to contradict their boss (or students their teacher)?

- Never

- Seldom

- Sometimes

- Usually

- Always

To what extent do you agree or disagree with each of the following statements? (please click one answer in each line across):

$1=$ Strongly agree

$2=$ Agree

$3=$ Undecided

$4=$ Disagree

5 = Strongly disagree

Q27: One can be a good manager without having a precise answer to every question that a subordinate may raise about his or her work.

$\begin{array}{lllll}1 & 2 & 3 & 4 & 5\end{array}$

Q28: Persistent efforts are the surest way to results.

$\begin{array}{lllll}1 & 2 & 3 & 4 & 5\end{array}$

Q29: An organization structure in which certain subordinates have two bosses should be avoided at all cost.

$\begin{array}{lllll}1 & 2 & 3 & 4 & 5\end{array}$

Q30: Company's or organization's rules should not be broken-not even when the employee thinks breaking the rule would be in the organization's best interest.

$\begin{array}{lllll}1 & 2 & 3 & 4 & 5\end{array}$

Thank you very much for your cooperation! 